\title{
Update on management of GIST and postsurgical use of imatinib
}

This article was published in the following Dove Press journal:

Open Access Surgery

9 August 2010

Number of times this article has been viewed

\section{E Pennacchioli \\ C Colombo \\ $M$ Berselli \\ A Gronchi}

Surgical Department, Melanoma and Sarcoma Unit, IRCCS Istituto dei

Tumori, Milan, Italy
Correspondence: Elisabetta Pennacchioli Melanoma and Sarcoma Unit, Surgical Dept, IRCCS Istituto dei Tumori v. Venezian I, 20133 Milan Italy Tel +39.0223902598

$\mathrm{Fax}+39.0223902404$

Email elisabetta.pennacchioli@ istitutotumori.mi.it
Abstract: The advent of imatinib is a milestone in the treatment for locally advanced and metastatic gastrointestinal stromal tumor (GIST) at a dose of $400 \mathrm{mg} /$ day. A higher starting dose of $800 \mathrm{mg}$ /day is recommended only for patients harboring the KIT exon 9 mutation. Studies of imatinib plasma levels are presently ongoing, possibly leading to dose adjustments in the single patient. In localized GIST, complete surgical excision (R0) is considered the standard treatment. Imatinib pretreatment is recommended if R0 surgery is not feasible, or if less mutilating surgery might be achieved by cytoreduction. Whenever surgical morbidity is expected to be an issue, imatinib should be considered even for resectable primary disease in the preoperative setting. Patients with completely resected primary GIST at significant risk of recurrence (based on tumor mitotic rate, size, and location) can be considered for adjuvant imatinib. Dose adjustments could be considered for exon 9 mutant GIST. Imatinib is well tolerated, and its side effects including nonhematologic (periorbital edema, fatigue, nausea, diarrhea, myalgia, skin rash, headache, and abdominal and chest pain) and hematologic (anemia, granulocytopenia, and particularly neutropenia) toxicities are usually mild, although the severity of adverse events increases with dose. While treatment should be continued indefinitely in advanced/metastatic patients, because its interruption is generally followed by relatively rapid tumor progression, the optimal duration of postoperative imatinib therapy is presently not known, even if it is likely that longer disease control will be obtained with longer treatment duration. Patients should be aware that it is not possible thus far to predict the impact of adjuvant therapy on survival. However, the impact on disease control has been dramatic, and imatinib represents a major step forward in the treatment of this rare disease.

Keywords: GIST, imatinib mesylate, adjuvant therapy

\section{Introduction}

Gastrointestinal stromal tumor (GIST) is the most common mesenchymal tumor of the gastrointestinal tract. Although rare as a clinical entity, it has received considerable attention as a model for the molecular treatment of cancer. GISTs are characterized by the presence of constitutively activated KIT (CD117), the tyrosine kinase receptor, also known as stem cell factor receptor, encoded by the c-KIT proto-oncogene. The proposed mechanism of constitutive KIT phosphorylation in the majority of GISTs is a gain-of-function mutation, most commonly involving exon 11, which encodes a portion of the cytoplasmic juxtamembrane domain. Other mutations involve exon 9 (extracellular domain), exon 13 (first part of the split tyrosine kinase domain) or exon 17 (phosphotransferase domain). Alternative oncogenic mechanisms in GISTs lacking c-KIT mutations are activating mutations in the platelet-derived growth factor receptor (PDGFR $\alpha)$ oncoprotein. 
The control of cellular processes, such as cell growth, division, and death, involves signal transduction, commonly including the transfer of phosphate from adenosine triphosphate to tyrosine residues on substrate proteins by tyrosine kinase enzymes. Activation of oncogenes coding for kinase proteins can lead to the production of kinases that are continually active, leading to increased cell proliferation and decreased apoptosis.

In order to develop specific targeted drugs, research has focused on oncogenic molecules and signal transduction pathways. One of those drugs is imatinib mesylate. GIST can be successfully treated with imatinib, with response rates of up to $85 \%$. However, complete responses are rare, and most patients experience imatinib resistance over time.

\section{Epidemiology}

The exact incidence of GIST is hard to determine. Recent studies report an incidence of about 10-15 cases/million/ year in Europe. However, the prevalence of GIST is higher, because many patients live for a number of years with the disease. At the time of diagnosis, the majority of patients with GIST are between 40 and 80 years of age, with a median age of approximately 60 years. Rarely, GIST can occur in children and in young adults. Most GISTs are sporadic, but familial GISTs are described. Some hereditary syndromes, including neurofibromatosis Type I, Carney's triad (gastric GIST, paraganglioma, and pulmonary chondroma) and Carney's dyad (paraganglioma and gastric GIST) can be associated with the development of the tumor. ${ }^{1,2}$

\section{Historic perspective}

Following their initial description in the 1940s, stromal tumors arising from the gastrointestinal tract were classified as smooth muscle neoplasms. ${ }^{3,4}$ Until the early 1960 s, these rare tumors were classified as various entities, including leiomyosarcoma, leiomyoblastoma, and bizarre leiomyoma. By the late 1960s, smooth muscle features were seen occasionally in GIST, raising the question of a smooth muscle origin for this entity. ${ }^{5,6}$ In addition, several authors reported ultrastructural features reminiscent of autonomic nerve structures, with schwannian and neuroaxonal characteristics in tumor specimens microscopically indistinguishable from GIST. ${ }^{7}$

With the introduction of immunohistochemistry in the early 1980s, it was soon appreciated that many of these tumors lacked the immunophenotypic features of smooth muscle and, conversely, a proportion of tumors stained positively for S100 protein, a marker for neuroectodermal differentiation. This led Mazur and Clark to suggest the myenteric nervous system cell as a possible origin and to introduce the more generic term "stromal tumor". In 1989, a distinctive subset of gastrointestinal tumors showing autonomic neural features was described and termed "plexosarcoma" and subsequently became better known as gastrointestinal autonomic nerve tumors (GANTs). ${ }^{8}$

From 1994, it became apparent that a significant proportion of GANTs were immunopositive for CD34, and for a while CD34 was believed to be the marker for GIST. This finding also raised the possibility that GIST might be related to the interstitial cells of Cajal (ICC) on the basis of CD34 immunopositivity. GISTs have immunophenotypic and ultrastructural characteristics of both neural and smooth muscle elements.

Until 1998, it was unclear what the cell of origin of GIST was, how to best diagnose GIST, or even how to distinguish malignant from benign GIST. Finally, in 1998, Hirota et al made two key discoveries, ie, a near-universal expression of KIT in GIST and the presence of activating c-KIT mutations. ${ }^{9}$ In Hirota's series of 49 GIST samples, $94 \%$ of cases expressed KIT. Mutations in the juxtamembrane domain of c-KIT were detected in five of six samples of GISTs, resulting in a constitutive ligand-independent activation of the KIT receptor, tyrosine kinase.

In the same year, work by Kindblom et al ${ }^{10}$ corroborated the findings of Hirota et al, showing that all of the 78 GISTs studied were immunoreactive for KIT, and shared striking ultrastructural and immunophenotypic similarities with ICC. This work supported the hypothesis that GISTs may develop from stem cells that differentiate toward the ICC phenotype and confirmed KIT as an accurate diagnostic tool for GIST.

The next decade saw phenomenal growth in the understanding of GIST biology and therapeutics, beginning with a single patient with an advanced, refractory GIST that displayed an early, rapid, and sustained response to a small molecule tyrosine kinase inhibitor, imatinib, with potent activity against the transmembrane receptor KIT, ABL kinase, and the chimeric BCR-ABL fusion oncoprotein product of chronic myeloid leukemia (CML). ${ }^{11}$ The remarkable, early clinical results led to large-scale, rationally designed clinical trials of imatinib in patients with GIST.

The introduction of tyrosine kinase inhibitors led to immense research interest in GIST. In 2003 Heinrich et al additionally identified PDGFR $\alpha$ gene mutations as an alternative pathogenetic event in GISTs lacking KIT gene mutations. ${ }^{12}$ To date, approximately $88 \%$ of GISTs are reported to harbor activating mutations in KIT or the homologous RTK gene, PDGFR $\alpha$, and KIT. Immunohistochemistry 
has proven to be a reliable and sensitive tool in GIST diagnosis.

\section{Oncogenetic mutations and signaling pathways}

KIT and PDGFR $\alpha$ genes map to chromosome $4 \mathrm{q} 12 .{ }^{13}$ Both of these genes encode Type III tyrosine kinase receptors sharing closely related structural features. These kinases are composed of an extracellular ligand-binding region containing five immunoglobulin-like repeats, a transmembrane sequence, a juxtamembrane domain, and two cytoplasmic kinase domains. KIT and PDGFR $\alpha$ are activated by binding of their respective ligands (stem cell factor and PDGF $\alpha$ ) to the extracellular region. In GISTs, KIT or PDGFR $\alpha$ mutations cause constitutive oncogenic signalling in the absence of their ligand, with alterations in the cell cycle, protein translocation, metabolism, and apoptosis.

\section{Clinical features}

GIST can occur from the esophagus to the anus. Gastric GISTs are the most common (about 60\%) and have many different forms and mutations. Thirty percent of GISTs are in the jejunum or ileum. Although the vast majority of GISTs smaller than $2 \mathrm{~cm}$ are essentially clinically benign, older classification in "benign or malignant" GIST has been replaced by risk stratification predicting clinical behavior. The parameters used in risk assessment for GIST according to the consensus National Comprehensive Cancer Network guidelines are mitotic index, size, and anatomic location ${ }^{14,15}$ (see Table 1).

The clinical presentation of GIST often depends on its site and location. As with many other mesenchymal neoplasms, a mass effect is responsible for symptoms. In many cases, GISTs can remain asymptomatic and be found incidentally. Patients can also present with microcytic anemia caused by erosion of GIST into the intestinal tract lumen.
A population-based study revealed that approximately $70 \%$ of GISTs were associated with clinical symptoms, $20 \%$ were not, and $10 \%$ were found at autopsy. ${ }^{16}$

Small GISTs present mainly as incidental findings during endoscopy, surgery, or radiologic investigation.

GISTs are often diagnosed only after resection and pathologic examination. Computed tomography (CT) and magnetic resonance imaging (MRI) are more able than other radiographic studies to suggest a diagnosis of GIST. GISTs usually involve the muscularis propria of the gastrointestinal wall, so the characteristic image is that of an intramural mass with exophytic growth.

Although metastatic spread to the thorax is rare, a CT scan of abdomen, pelvis, and thorax is necessary for accurate staging. CT also supplies the technical information necessary to determine whether surgical resection is feasible. Positron emission tomography (PET) is sensitive, but not specific, to diagnose GISTs. This method can be used more appropriately to evaluate treatment response.

Preoperative biopsy is useful to confirm the diagnosis and to exclude other malignancies, but is not mandatory for small and easily resectable GISTs. Biopsy is recommended for incidental endoscopically-suspected GIST to rule out other benign conditions that cannot be resected, and is mandatory if preoperative treatment can be considered. Indeed, if there is a mass, especially if surgery is likely to be a multivisceral resection, biopsy is considered the standard approach. This is a helpful tool in planning the best approach according to the histologic findings. ${ }^{17}$

Pathologic review plays a central role in the diagnosis and treatment of patients with GIST, given that the objective clinical response to imatinib has been demonstrated to depend on the tyrosine kinase receptor mutation. In addition, mutational analysis of KIT and PDGFR $\alpha$ genes can confirm the diagnosis of GIST and have predictive and prognostic value. Centralization of mutational analysis in a laboratory enrolled

Table I Risk stratification of primary GIST

\begin{tabular}{|c|c|c|c|c|c|}
\hline \multicolumn{6}{|c|}{ Risk stratification of primary GIST } \\
\hline \multicolumn{2}{|c|}{ Tumor parameter } & \multicolumn{4}{|c|}{ Risk of progressive disease ${ }^{a}$} \\
\hline Mitotic index & Size & Gastric & Duodenum & Jejunum/ileum & Rectum \\
\hline$\leq 5 / 50 \mathrm{HPF}$ & $\leq 2 \mathrm{~cm}$ & None & None & None & None \\
\hline$\leq 5 / 50 \mathrm{HPF}$ & $>2 \leq 5 \mathrm{~cm}$ & Very low (1.9\%) & Low (8.3\%) & Low (4.3\%) & Low $(8.5 \%)$ \\
\hline$\leq 5 / 50 \mathrm{HPF}$ & $>5 \leq 10 \mathrm{~cm}$ & Low (3.6\%) & $--^{c}$ & Moderate $(24 \%)$ & $--^{c}$ \\
\hline$\leq 5 / 50 \mathrm{HPF}$ & $>10 \mathrm{~cm}$ & Moderate $(10 \%)$ & High (34\%) & High (52\%) & High (57\%) \\
\hline$>5 / 50 \mathrm{HPF}$ & $\leq 2 \mathrm{~cm}$ & None ${ }^{b}$ & $--^{c}$ & High $^{\mathrm{b}}$ & High (54\%) \\
\hline$>5 / 50 \mathrm{HPF}$ & $>2 \leq 5 \mathrm{~cm}$ & Moderate (16\%) & High (50\%) & High (73\%) & High (52\%) \\
\hline$>5 / 50 \mathrm{HPF}$ & $>5 \leq 10 \mathrm{~cm}$ & High (55\%) & $--^{c}$ & High (85\%) & $-c$ \\
\hline$>5 / 50 \mathrm{HPF}$ & $>10 \mathrm{~cm}$ & High (86\%) & High (86\%) & High (90\%) & High (7I\%) \\
\hline
\end{tabular}

Notes: adefined as metastasis or tumor-related death; 'bmall number of cases; ${ }^{\mathrm{b}}$ no tumors of such categories were included in the study. 
in an external quality assurance program and with expertise in the disease may be useful in order to make mutational analysis more widely available. Mutational analysis is currently recommended in the diagnostic work-up of all GISTs. ${ }^{17}$ The objective response rates for KIT exon 11 mutant GISTs, KIT 9 exon mutant GISTs, and wild-type GISTs are $72 \%-86 \%$, $48 \%-38 \%$, and up to $28 \%$ respectively. ${ }^{14,18-22}$ PDGRF $\alpha$ mutant GISTs have been shown to respond to imatinib, with the exception of the exon 18 D842V mutation. ${ }^{18,19,23}$

\section{Surgical treatment}

The standard treatment for localised GIST is surgery, with R0 resection being the goal. Given the usual exophytic growth pattern of GIST within the gastrointestinal tract, wedge or segmental resections are often possible. In locations where wedge resection is not technically feasible, wide resections or en bloc resections can be performed to achieve grossly negative surgical margins. Lymphadenectomy is not required.

If R0 surgery is not feasible, or might be achieved through less mutilating surgery by cytoreduction, imatinib pretreatment is recommended. This may also be the case if the surgeon believes that the surgical procedure would be safer after cytoreduction. Surgery is performed following maximal tumor response to therapy, generally after 6-12 months. Mutational analysis may help to exclude nonsensitive mutations from surgical treatment. PET scan, or PET-CT/MRI, may be particularly useful to assess tumor response very rapidly, in terms of a few weeks, so that surgery is not delayed in the case of nonresponsive disease. ${ }^{17}$ Imatinib is the standard treatment in locally advanced, inoperable, and metastatic patients. This is also the case in metastatic patients in whom lesions have been surgically excised after incidental discovery. Complete excision of residual metastatic disease has been shown to be related to a better prognosis, provided that the patient is responding to imatinib, but it is not as yet known whether this is due to surgery or to selection bias.

\section{Clinical efficacy of imatinib} as adjuvant treatment after surgery

Surgery is the mainstay of curative treatment for patients with primary resectable GIST. Despite R0 surgical resection of GIST, a postoperative recurrence risk is reported to vary between $0 \%$ and $90 \%$, depending on the characteristics of the tumor. Historically, the five-year survival rate following surgical treatment of primary GIST is $54 \%{ }^{24}$ Knowing the risk of recurrence can help clinicians to evaluate the best therapeutic strategy following surgery. Predictive factors for recurrence are the size of the tumor, location of the tumor, mitotic count, and mutational status. ${ }^{25,26}$ The use of imatinib as an adjuvant treatment in patients with primary resectable GIST has been reported in small, nonrandomized, single-institution studies. ${ }^{27-29}$ A larger, multi-institution Phase II study of postoperative imatinib in patients with very-high risk GIST has been conducted. In this trial, treatment was administered for 1 year after surgery; $82 \%$ of patients completed treatment and without important toxicity. ${ }^{30}$ A subsequent randomized, placebo-controlled Phase III trial of adjuvant imatinib in patients with GIST at least $3 \mathrm{~cm}$ in diameter was done (American College of Surgeons Oncology Group Adjuvant Trial Z9001). The trial was not blinded, and an interim analysis has shown that patients receiving treatment had a statistically significant increase in recurrence-free survival. Seven hundred and thirteen patients having a histologic diagnosis of KIT-positive GIST, tumor size $\geq 3 \mathrm{~cm}$, and complete gross resection within 14 to 70 days prior to registration were enrolled in this study. Patients were randomized to receive imatinib at a dose of $400 \mathrm{mg} /$ day or placebo for one year. The primary endpoint of this study was recurrence-free survival. At the end of the 1 -year treatment period, an estimated $98 \%$ of patients in the treatment group achieved recurrence-free survival at 1 year, compared with $82 \%$ of patients in the placebo group. This yielded a $16 \%$ absolute risk reduction, and the difference in recurrence-free survival between the two groups was statistically significant $(P=0001)$. This difference was observed as early as 6 months, and was even more pronounced in patients with tumors larger than $10 \mathrm{~cm}$. Based on the results of this trial, the US Food and Drug Administration (FDA) approved the use of imatinib at a dose of $400 \mathrm{mg} /$ daily in the adjuvant setting of patients with GIST larger than $3 \mathrm{~cm} .{ }^{31}$ The optimal duration of therapy has not been determined.

Two other large trials in Europe are investigating the adjuvant use of imatinib. The Phase III trial EORTC/GSF/ ISG/GEIS/AGIT 62024 is a controlled, randomized trial comparing adjuvant imatinib administered for two years, at a daily dose of $400 \mathrm{mg}$, versus no treatment after complete resection of intermediate- and high-risk GIST. The risk stratification in this study is based on tumor diameter and mitotic index. The multicenter study SSGXVIII/AIO is a randomized Phase III trial comparing one and three years of adjuvant therapy with imatinib at a daily dose of $400 \mathrm{mg}$ in patients with high-risk GIST. This study addresses the issue of optimal duration of treatment.

The current evidence is that there is an early recurrencefree survival advantage for adjuvant imatinib in GIST, but it is not yet known if this early advantage will translate into a 
longer-term benefit. The other issue to evaluate is the specific patient population likely to benefit from adjuvant treatment. We are currently proposing adjuvant therapy on the basis of known risk factors, ie, mitotic index, tumor size and site, and mutational status. In the future, tailored adjuvant therapy to specific subgroups of patients could be feasible.

\section{Pharmacology}

Imatinib, formerly known as STI751, is a competitive antagonist of the adenosine triphosphate binding site of several receptors, including ABL, ABL-related gene product (ARG), KIT, CSF-1R, PDGFR $\alpha$, and PDGFR $\beta .{ }^{32,33}$ It blocks the transfer of phosphate groups from adenosine triphosphate to tyrosine kinase residues of the substrates. This causes interruption of the downstream process of the mitogen-activated protein kinase and Akt signalling pathways implicated in cell proliferation and survival. ${ }^{34,35}$

Imatinib was first used as a therapeutic agent in CML, in which the tyrosine kinase BCR-ABL, the fusion product of the Philadelphia chromosome, is constitutively activated. ${ }^{36}$ All patients in the chronic phase of CML treated with imatinib showed a complete response. Proliferation and tumor formation by cells expressing BCR-AB were inhibited by imatinib in vitro. The concentration of imatinib required to inhibit cellular tyrosine phosphorylation by $50 \%\left(\mathrm{IC}_{50}\right)$ was $0.25 \mu \mathrm{M}$ in BCR-ABL-expressing cell lines. ${ }^{35}$ At the same concentration, imatinib is able to inhibit the kinase activity of c-kit in vitro. ${ }^{34}$

In the late 1990s, it was discovered that the malignant behavior of GIST is due to gain-of-function mutations in the genes encoding for the c-kit receptor ${ }^{9}$ or for PDGFR $\alpha .^{12}$ These mutations result in autophosphorylation of c-kit and PDGFR $\alpha$, uncontrolled cell proliferation, and stimulation of downstream signalling pathways, including those involving phosphatidyl inositol 3 kinase and mitogen-activated protein kinases.

About $80 \%-86 \%$ of GISTs have primary KIT mutations. ${ }^{37}$ Most of them involve the juxtamembrane domain (exon 11), but other exons harboring mutations have been described, such as exon 9 (extracellular domain) with a frequency of 5\%-18\% and exons 13 (kinase 1 domain) and 17 (activation loop) with frequencies of $1.5 \%-4.5 \%{ }^{9,38}$ (Figure 1). Of the GISTs not harboring KIT mutations, around $10 \%$ have mutations in the second kinase domain of PDGFR $\alpha$ (exon 18), almost twothirds of which consist of a single point mutation (D842V). ${ }^{39}$ KIT and PDGFR $\alpha$ mutations are mutually exclusive, but they lead constitutively to the activation of tyrosine kinase which is involved in cell proliferation and survival. ${ }^{37}$
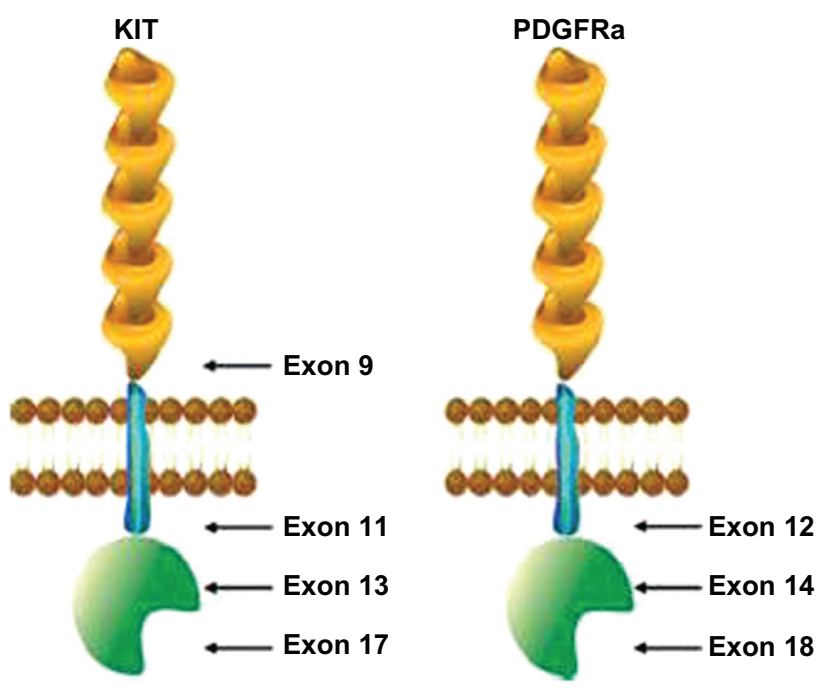

Figure I KIT and platelet-derived growth factor receptor alpha mutation.

Imatinib mesylate is designated chemically as 4-[(4-Methyl-1-piperazinyl) methyl]-N-[4-methyl-3(pyridinyl)-2]amino]-phenyl]benzamide methane-sulfonate (Figure 2). It is a crystalline powder, with a molecular formula of $\mathrm{C}_{29} \mathrm{H}_{31} \mathrm{~N}_{7} \mathrm{OCH}_{4} \mathrm{SO}_{3}$ and a molecular weight of 589.7. Its structure mimics that of adenosine triphosphate.
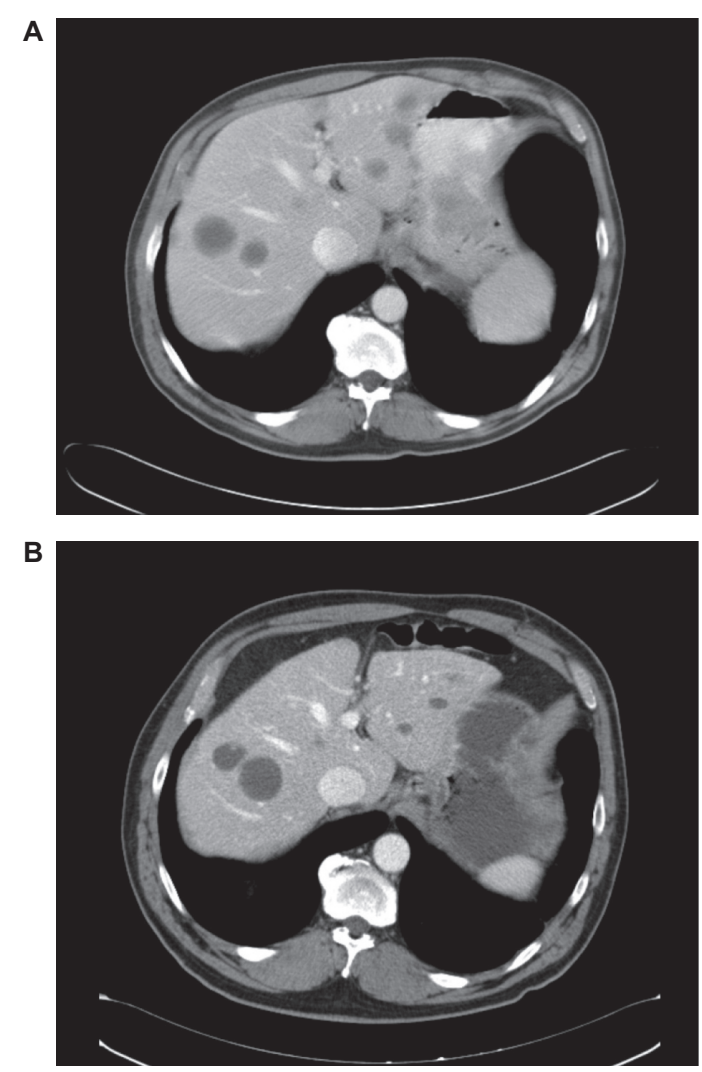

Figure 2 Computed tomography scan imaging. Comparison between $\mathbf{A}$ ) before and $\mathbf{B}$ ) after imatinib treatment in a gastrointestinal stromal tumor with liver metastases. 
Imatinib is well absorbed after oral administration, with mean maximum plasma concentration $\left(\mathrm{C}_{\max }\right)$ achieved within 2-4 hours after dosing and a mean absolute bioavailability of $98 \%$ for the capsule formulation. ${ }^{40}$ The bioavailability and other pharmacokinetic characteristics of imatinib are not affected by oral consumption of a fat-rich meal. ${ }^{41} \mathrm{~A}_{\text {mean }} \mathrm{C}_{\max }$ of $2.3 \mathrm{mg} / \mathrm{L}$ at steady state was obtained from imatinib $400 \mathrm{mg} /$ day in 83 adult patients with chronic CML. ${ }^{36}$ At steady state, the mean plasma concentration was $0.72 \mathrm{mg} / \mathrm{L}$, which exceeds the $\mathrm{IC}_{50}$ of the drug required to inhibit proliferation of BCR-ABL-positive leukemic cells obtained from patients with CML. ${ }^{35}$

The pharmacokinetics of imatinib did not change significantly with repeated doses. The mean imatinib area under the plasma concentration-time curve increases proportionally with increasing doses of $25-1000 \mathrm{mg}$. Accumulation is 1.5-fold to 2.5 -fold at steady state when imatinib is administered once daily. ${ }^{36,40,42}$

In in vitro experiments, plasma protein binding (predominantly to albumin and $\alpha 1$-acid glycoprotein) was about $95 \%$ at clinically relevant concentrations. ${ }^{43}$ The major enzyme responsible for the metabolism of imatinib is cytochrome P450 (CYP) 3A4, although other isozymes (CYP1 A2, CYP 2D6, CYP 2C9, and CYP2 C19) play a minor role.

In cases of concomitant administration of CYP $3 \mathrm{~A} 4$ inducers (ie, dexamethasone, phenytoin, carbamazepine, rifampin, rifabutin, rifampicin, phenobarbital), the daily imatinib dose should be increased, with careful monitoring of clinical response. Drugs that decrease CYP3 A4 activity (eg, ketoconazole, clarithromycin, atazanavir) may decrease imatinib metabolism, so a reduction in daily dose should be considered. ${ }^{42,44}$

A decreased dose is recommended in patients with severe hepatic insufficiency or renal impairment. The latter group of patients should receive a dose not greater than $600 \mathrm{mg}$ in case of mild renal failure and not greater than $400 \mathrm{mg}$ in case of moderate insufficiency.

After oral administration, the elimination half-lives of imatinib and its major metabolite (N-demethyl derivative, CGP74588) in healthy volunteers are approximately 18 and 40 hours, respectively. ${ }^{42}$ Imatinib elimination is predominantly via feces (68\%) and urine (13\%), and mostly as metabolites. Clearance of imatinib is expected to be $8 \mathrm{~L} /$ hour for a 50 -yearold patient weighing $50 \mathrm{~kg}$. It is not necessary to adjust the initial dosage based on body weight or age, but the patient should be monitored for any treatment-related toxicity.

\section{Efficacy study}

In 2001, on the basis of the demonstrated efficacy of imatinib in cell lines harboring KIT mutations, ${ }^{26}$ Joensuu et al successfully treated the first patient, a 50-year-old woman with rapidly progressive metastatic disease, in whom a complete metabolic response was demonstrated by a PET scan obtained after one month of therapy. The anticancer activity of imatinib was confirmed by multiple biopsies of liver lesions. ${ }^{11}$

After this observation, a multi-institutional Phase I study was conducted demonstrating the efficacy of imatinib in advanced metastatic disease. ${ }^{45}$ Further Phase II studies conducted at the same time in Europe and the US showed clinical evidence of the efficacy of imatinib in GIST in terms of objective response..$^{46,47}$

As a result of two randomized clinical trials demonstrating median progression-free survival of 2 years ${ }^{48}$ and an increase in median overall survival to 4.8 years with 64 months of follow-up, ${ }^{21}$ imatinib is now considered standard treatment in locally advanced and metastatic patients. ${ }^{14,17}$

A study in the pre-imatinib era showed that 80 of 200 patients with likely GIST were able to undergo complete resection. These patients had a median survival time of 60 months, and those with metastatic disease had a median survival of around 20 months. ${ }^{49}$ Treatment with imatinib has changed the natural course of this disease, and in a study including patients with advanced (unresectable or metastatic) GIST, overall survival was 3.5 years. ${ }^{19}$

The standard dose of imatinib is $400 \mathrm{mg}$ daily. Both the European and US dose efficacy trials ${ }^{48,50}$ demonstrated similar results in terms of objective response in patients treated with imatinib $400 \mathrm{mg}$ and $800 \mathrm{mg}$ daily. Although imatinib was initially approved at doses of 400 and $600 \mathrm{mg}$ daily, the use of high-dose imatinib ( $800 \mathrm{mg}$ daily) has shown a benefit in patients with advanced or metastatic GIST who progress on the standard dose. In patients harboring exon 9 mutations who have an initial partial response to the conventional dose, a superior progression-free survival with the high-dose regimen can be obtained. ${ }^{19,51}$ This result was related to responses to the dose increase (assessed using a growth modulation index), occurring most often in patients without detectable kinase mutations $(83 \%)$ and in those with KIT exon 9 mutations $(57 \%) .{ }^{52}$ Mutational analysis may help to identify patients with mutations (eg, PDGFR $\alpha$ mutation involving exon 18 with a substitution in codon D842V) unsuitable for imatinib therapy. An objective clinical response to imatinib correlates with KIT mutation status, with the best response rate seen for patients with mutations in KIT exon $11^{37}$ (Figure 2).

The use of imatinib after complete resection of primary GIST was evaluated in a multicenter, randomized, doubleblind, placebo-controlled trial led by the American College 
of Surgeons Oncology Group, and sponsored by the Cancer Therapy Evaluation Program and Novartis, involving 713 high-risk patients. High risk was defined as a tumor size $>10 \mathrm{~cm}$, intraperitoneal tumor rupture or hemorrhage, or multifocal (more than five) tumors.

Patients assigned to the imatinib arm and placebo arm had a one-year recurrence-free survival of $97 \%$, and $83 \%$, respectively $(P<0.001)$. The data from this study have shown that 1 year of imatinib is well tolerated in the adjuvant setting, prolongs recurrence-free survival, and is associated with improved overall survival when compared with historic controls. $^{53}$

The optimal duration of imatinib therapy is not completely defined. In a French study, interruption of treatment after one year was associated with a high risk of relapse, and reintroduction was correlated with response. Treatment should continue until progression, intolerance, or patient refusal to undergo further treatment. ${ }^{54}$

\section{Safety and tolerability}

Imatinib is well tolerated, and its side effects are usually mild, although the severity of adverse events increases with dose. ${ }^{20}$ Adverse effects are described not only in the clinical trials conducted under widely varying conditions but also in clinical practice. Development of toxicity and side effects can cause interruption of treatment, occurring more frequently with high-dose therapy. To avoid disease recurrence, all patients receiving imatinib therapy should receive continuous treatment, because treatment interruption results in disease progression at a median of six months..$^{20,55}$

Observation of dose-related toxicity is common in all the clinical trials. The incidence of mild adverse events is frequent $(99 \%)$ and similar in patients receiving low- or high-dose therapy (600 or $800 \mathrm{mg}$ daily), and their severity increases with at higher doses. ${ }^{21,48}$ In a Phase III study assessing two different doses, the rate of Grade 3-4 adverse effects was $32.3 \%$ in the group receiving $400 \mathrm{mg}$ /day versus $50.2 \%$ in the group receiving $800 \mathrm{mg} /$ day. $^{20}$

The most commonly observed nonhematologic toxicities in patients receiving high-dose imatinib include edema (mainly periorbital), fatigue, nausea, diarrhea, myalgia or musculoskeletal pain, skin rash, headache, and abdominal and chest pain. Dose reductions in patients receiving imatinib $800 \mathrm{mg}$ daily have been shown to be mainly because of edema, nausea, and fatigue. ${ }^{21}$ In contrast with patients receiving imatinib for CML, cardiovascular and myelosuppressive events rarely occur in GIST patients and are not dose-related. ${ }^{45,56}$ The most frequently reported hematologic side effects include anemia (dose-related $)^{21,48}$ and granulocytopenia, particularly neutropenia (independent of dose). ${ }^{57}$ Thrombocytopenia and hemorrhage have also been observed..$^{21} 48$

Studies conducted in rats have demonstrated that imatinib can induce carcinogenesis at $60 \mathrm{mg} / \mathrm{kg} /$ day in target organs (including kidney, urinary bladder, and small intestine) and is teratogenic in rats, so should be avoided in pregnant women and in breast-feeding women given that imatinib and its metabolites, known to be secreted in rat milk, could be present in human milk.

\section{Conclusions}

Imatinib is the cornerstone of treatment for advanced metastatic GIST at a dose of $400 \mathrm{mg} /$ day. A higher starting dose of $800 \mathrm{mg} /$ day is recommended for patients harboring kit exon 9 mutations. Studies of imatinib plasma levels are presently underway and will possibly lead to dose adjustments in individual patients.

Whenever expected surgical morbidity is an issue, imatinib should be considered even for resectable primary disease in the preoperative setting. The aim of treatment is to preserve organs and function as much as possible, in order to improve the short- and long-term surgical outcome.

Patients with completely resected primary GIST at significant risk of recurrence can be considered for adjuvant imatinib. Dose adjustments could be considered for exon 9 mutant GIST. The optimal duration of postoperative imatinib therapy is presently not known, but it is likely that longer disease control will be obtained with longer treatment duration. Discussion with patients should also acknowledge that we still cannot predict the impact of adjuvant therapy on survival. However, the impact on disease control has been dramatic and represents a major step forward in the treatment of this rare disease.

\section{Disclosure}

The authors disclose no conflicts of interest.

\section{References}

1. Andersson J, Sihto H, Meis-Kindblom JM, et al. NF1-associated gastrointestinal stromal tumors have unique clinical, phenotypic and genotypic characteristics. Am J Surg Pathol. 2005;29(9):1170-1176.

2. Carney JA. Gastric stromal sarcoma, pulmonary chondroma and extra-adrenal paraganglioma (Carney triad): Natural history, adrenocortical component and possible familial occurrence. Mayo Clin Proc. 1999;74(6):543-552.

3. Stout AP. Bizarre smooth muscle tumors of the stomach. Cancer. 1962; $15: 400$

4. Somerhausen N, de S, Fletcher CD. Gastrointestinal stromal tumours: An update. Sarcoma. 1998;2(3-4):133-141.

5. Welsh RA, Meyer AT. Ultrastructure of gastric leiomyoma. Arch Pathol. 1969;87(1):71-81. 
6. Weiss RA, Mackay B. Malignant smooth muscle tumors of the gastrointestinal tract: An ultrastructural study of 20 cases. Ultrastruct Pathol. 1981;2(3):231-240.

7. Yagihashi S, Kimura M, Kurotaki H, et al. Gastric submucosal tumours of neurogenic origin with neuroaxonal and Schwann cell elements. J Pathol. 1987;153(1):41-50.

8. Lauwers GY, Erlandson RA, Casper ES, et al. Gastrointestinal autonomic nerve tumors. A clinicopathological, immunohistochemical, and ultrastructural study of 12 cases. Am J Surg Pathol. 1993;17(9):887-897.

9. Hirota S, Isozaki K, Moriyama Y, et al. Gain-of-function mutations of c-kit in human gastrointestinal stromal tumors. Science. 1998;279(5350):577-580.

10. Kindblom LG, Remotti HE, Aldenborg F, et al. Gastrointestinal pacemaker cell tumor (GIPACT): Gastrointestinal stromal tumors show phenotypic characteristics of the interstitial cells of Cajal. Am J Pathol. 1998;152(5):1259-1269.

11. Joensuu H, Roberts PJ, Sarlomo-Rikala M, et al. Effect of the tyrosine kinase inhibitor STI571 in a patient with a metastatic gastrointestinal stromal tumor. N Engl J Med. 2001;344(14):1052-1056.

12. Heinrich MC, Corless CL, Duesing A, et al. PDGFRA activating mutations in gastrointestinal stromal tumors. Science. 2003; 299(5607):708-710.

13. Stenman G, Eriksson A, Claesson-Welsh L. Human PDGFA receptor genes maps to the same region on chromosome 4 as the KIT oncogene. Genes Chromosomes Cancer. 1989;1(2):155-158.

14. Demetri GD, Benjamin RS, Blanke CD, et al. NCCN Task force report: Management of patients with gastrointestinal stromal tumor (GIST) update of the NCCN clinical practice guidelines. J Natl Compr Canc Netw. 2007;5(Supp1 2):S1-S29.

15. Miettinen M, Lasota J. Gastrointestinal stromal tumors: Pathology and prognosis at different sites. Semin Diagn Pathol. 2006;23(2):70-83.

16. Nilsson B, Bumming P, Meis-Kindblom JM, et al. Gastrointestinal stromal tumors: The incidence, prevalence, clinical course and prognostication in the preimatinib mesylate era. A population-based study in Western Sweden. Cancer. 2005;103(4):821-829.

17. Casali PG, Jost L, Reichardt P, Schlemmer M, Blay J-Y; ESMO Guidelines Working Group. Gastrointestinal stromal tumors: ESMO clinical recommendations for diagnosis, treatment and follow-up. Ann Oncol. 2008;19 Suppl 2:ii35-ii8.

18. Heinrich MC, Corless CL, Demetri GD, et al. Kinase mutations and imatinib response in patients with metastatic gastrointestinal stromal tumor. J Clin Oncol. 2003;21(23):4342-4349.

19. Debiec-Rychter M, Sciot R, Le Cesne A, et al. KIT mutations and dose selection for imatinib in patients with advanced gastrointestinal stromal tumours. Eur J Cancer. 2006;42(8):1093-1103.

20. Blanke CD, Demetri GD, von Mehren M, et al. Long-term results from a randomized Phase II trial of standard- versus higher-dose imatinib mesylate for patients with unresectable or metastatic gastrointestinal stromal tumors expressing KIT. J Clin Oncol. 2008;26(4):620-625.

21. Blanke CD, Rankin C, Demetri GD, et al. Phase III randomized, Intergroup trial assessing imatinib mesylate at two dose levels in patients with unresectable or metastatic gastrointestinal stromal tumors expressing the kit receptor tyrosine kinase: S0033. J Clin Oncol. 2008;26(4):626-632.

22. Heinrich MC, Corless CL, Blanke CD, et al. Molecular correlates of imatinib resistance in gastrointestinal stromal tumors. J Clin Oncol. 2006;24(29):4764-4774.

23. Hirota S, Ohashi A, Nishida T, et al. Gain-of-function mutations of platelet-derived growth factor receptor alpha gene in gastrointestinal stromal tumors. Gastroenterology. 2003;125(3):660-667.

24. National Comprehensive Cancer Network. NCCN Clinical Practice Guidelines in Oncology. Soft tissue sarcoma. http://www.nccn.org. Accessed April 27, 2009.

25. DeMatteo RP, Gold JS, Saran L, et al. Tumor mitotic rate, size and location independently predict recurrence after resection of primary gastrointestinal stromal tumor (GIST). Cancer. 2008;112(3):608-615.
26. Miettinen M, Lasota J. Gastrointestinal stromal tumors: Review on morphology, molecular pathology, prognosis and differential diagnosis. Arch Pathol Lab Med. 2006;130(10):1466-1478.

27. Benjamin RS, Blanke CD, Blay JY, Bonvalot S, Eisenberg B. Management of gastrointestinal stromal tumors in the imatinib era: Selected case series. Oncologist. 2006;11(1):9-20.

28. Lai IR, Hu RH, Chang KJ. Is imatinib justified as an adjuvant chemotherapy in patients with recurrent gastrointestinal stromal tumors? Hepatogastroenterology. 2005;52(63):826-828.

29. Nilsson B, Sjolund K, Kindblom LG, et al. Adjuvant imatinib treatment improves recurrence-free survival in patients with high-risk gastrointestinal stromal tumors (GIST). Br J Cancer. 2007;96(11):1656-1658.

30. DeMatteo RP, Antonescu CR, Chadaram V, et al. Adjuvant imatinib mesylate in patients with primary high risk gastrointestinal stromal tumor (GIST) following complete resection: Safety results from the US Intergroup Phase II trial ACOSOG Z9000. J Clin Oncol. 2005;23:Abstr 9009 .

31. Cohen MH, Cortazar P, Justice R, Pazdur R. Approval summary: Imatinib mesylate in the adjuvant treatment of malignant gastrointestinal stromal tumor. Oncologist. 2010;15(3):300-307.

32. Buchdunger E, Cioffi CL, Law N, et al. Abl protein-tyrosine kinase inhibitor STI571 inhibits in vitro signal transduction mediated by c-Kit and platelet-derived growth factor receptors. $J$ Pharmacol Exp Ther. 2000;295(1):139-145.

33. Okuda K, Weisberg E, Gilliland DG, Griffin JD. ARG tyrosine kinase activity is inhibited by STI571. Blood. 2001;97(8):2440-2448.

34. Heinrich MC, Griffith DJ, Druker BJ, Wait CL, Ott KA, Zigler AJ. Inhibition of c-kit receptor tyrosine kinase activity by STI 571, a selective tyrosine kinase inhibitor. Blood. 2000;96(3):925-932.

35. Druker BJ, Tamura S, Buchdunger E, et al. Effects of a selective inhibitor of the Abl tyrosine kinase on the growth of Bcr-Abl positive cells. Nat Med. 1996;2:561-566.

36. Druker BJ, Talpaz M, Resta DJ, et al. Efficacy and safety of a specific inhibitor of the BCR-ABL tyrosine kinase in chronic myeloid leukemia. N Engl J Med. 2001;344(14):1031-1037.

37. Miettinen M, Sobin LH, Lasota J. Gastrointestinal stromal tumors of the stomach: A clinicopathologic, immunohistochemical, and molecular genetic study of 1765 cases with longterm follow-up. Am J Surg Pathol. 2005;29(1):52-68.

38. Corless CL, Fletcher JA, Heinrich MC. Biology of gastrointestinal stromal tumors. Clin Oncol. 2004;22(18):3813-3825.

39. Corless CL, Schroeder A, Griffith D, et al. PDGFRA mutations in gastrointestinal stromal tumors: Frequency, spectrum and in vitro sensitivity to imatinib. J Clin Oncol. 2005;23(23):5357-5364.

40. Peng B, Hayes M, Resta D, et al. Pharmacokinetics and pharmacodynamics of imatinib in a Phase I trial with chronic myeloid leukemia patients. J Clin Oncol. 2004;22(5):935-942.

41. Reckmann A, Fischer T, Peng B, et al. Effect of food on STI571 Glivec pharmacokinetics and bioavailability. Proc Am Soc. Clin Oncol. 2001;20:307a

42. Imatinib [package insert]. East Hanover, NJ. Novartis Pharmaceuticals Corporation, 2002.

43. Kretz O, Weiss HM, Schumacher MM, Gross G. In vitro blood distribution and plasma protein binding of the tyrosine kinase inhibitor imatinib and its active metabolite, CGP74588, in rat, mouse, dog, monkey, healthy humans and patients with acute lymphatic leukaemia. Br JClin Pharmacol. 2004;58(2):212-216.

44. Dutreix C, Peng B, Mehring G, et al. Ketoconazole increases imatinib (Glivec ${ }^{\circledR} /$ STI571) exposure: Results of a drug-drug interaction study. Blood. 2002;100:214b.

45. van Oosterom AT, Judson I, Verweij J, et al. Safety and efficacy of imatinib (STI571) in metastatic gastrointestinal stromal tumours: A Phase I study. Lancet. 2001;358:1421-1423.

46. Demetri GD, von Mehren M, Blanke CD, et al. Efficacy and safety of imatinib mesylate in advanced gastrointestinal stromal tumors. $N$ Engl J Med. 2002;347:472-480. 
47. Verweij J, van Oosterom A, Blay JY, et al. Imatinib mesylate (STI-571, Glivec, Gleevec) is an active agent for gastrointestinal stromal tumours, but does not yield responses in other soft-tissue sarcomas that are unselected for a molecular target. Results from an EORTC Soft Tissue and Bone Sarcoma Group phase II study. Eur J Cancer. 2003;39:2006-2011.

48. Verweij J, Casali PG, Zalcberg J, et al. Progression-free survival in gastrointestinal stromal tumours with high-dose imatinib: Randomised trial. Lancet. 2004;364:1127-1134.

49. Dematteo RP, Lewis JJ, Leung D, et al. Two hundred gastrointestinal stromal tumors: Recurrence patterns and prognostic factors for survival. Ann Surg. 2000;231:51-58.

50. Rankin C, von Mehren M, Blanke C, et al. Collaborating Investigators of the North American Sarcoma Intergroup. Dose effect of imatinib (IM) in patients (pts) with metastatic GIST. Phase III Sarcoma Group Study S0033. Proc Am Soc Clin Oncol. 2004;23:815.

51. van Glabbeke MM, Owzar K, Rankin C, et al. Comparison of 2 doses of imatinib for the treatment of unresectable or metastatic gastrointestinal stromal tumors (GIST): A meta-analysis based on 1,640 patients. Presented at: American Society of Clinical Oncology 43rd Annual Meeting; 2007 Jun 1-5, Chicago, IL.

52. Zalcberg JR, Verweij J, Casali P, et al. Outcome of patients with advanced gastrointestinal stromal tumours crossing over to a daily imatinib dose of $800 \mathrm{mg}$ after progression on $400 \mathrm{mg}$. Eur J Cancer. 2005;41:1751-1757.
53. DeMatteo RP, Owzar K, Antonescu CR, et al. Efficacy of adjuvant imatinib mesylate following complete resection of localized, primary gastrointestinal stromal tumor (GIST) at high risk of recurrence: The U.S. Intergroup Phase II trial ACOSOG Z9000. J Clin Oncol. 2005;23(16S):9009.

54. Blay JY, Le Cesne A, Ray-Coquard I, et al. Prospective multicentric randomized Phase III study of imatinib in patients with advanced gastrointestinal stromal tumors comparing interruption versus continuation of treatment beyond 1 year: The French Sarcoma Group. J Clin Oncol. 2007;25:1107-1113.

55. Adenis A, Cassier PA, Bui BN, et al. Does interruption of imatinib (IM) in responding patients after 3 years of treatment influence outcome of patients with advanced GIST included in the BFR14 trial. J Clin Oncol. 2008;26 Suppl:558s

56. Verweij J, Casali PG, Kotasek D, et al. Imatinib does not induce cardiac left ventricular failure in gastrointestinal stromal tumours patients: analysis of EORTC-ISG-AGITG study 62005. Eur J Cancer. 2007;43:974-978.

57. van Glabbeke M, Verweij J, Casali PG, et al. Predicting toxicities for patients with advanced gastrointestinal stromal tumours treated with imatinib: A study of the European Organisation for Research and Treatment of Cancer, the Italian Sarcoma Group, and the Australasian Gastro-Intestinal Trials Group (EORTC-ISG-AGITG). Eur J Cancer. 2006;42:2277-2285.
Open Access Surgery

\section{Publish your work in this journal}

Open Access Surgery is an international, peer-reviewed, open access journal that focuses on all aspects of surgical procedures and interventions. Patient care around the peri-operative period and patient outcomes post surgery are key topics. All grades of surgery from minor cosmetic interventions to major surgical procedures are covered. Novel techniques

\section{Dovepress}

and the utilization of new instruments and materials, including implants and prostheses that optimize outcomes constitute major areas of interest. The manuscript management system is completely online and includes a very quick and fair peer-review system. Visit http://www.dovepress.com/ testimonials.php to read real quotes from published authors. 